\title{
Parametric Optimisation of Micro Plasma Welding for Wire Arc Additive Manu- facturing by Response Surface Methodology
}

\author{
Nor Ana Rosli (0000-0002-2467-3424) ${ }^{1}$, Mohd Rizal Alkahari (0000-0001-7164-5859) ${ }^{1,2}$, Faiz Redza Ramli (0000- \\ 0002-7351-7137) 1,3, Mohd Fadzli bin Abdollah (0000-0002-2460-2888)1,3, Syahibudil Ikhwan Abdul Kudus (0000- \\ 0003-0703-9197)4, Safarudin Gazali Herawan (0000-0002-5725-8075) \\ ${ }^{1}$ Fakulti Kejuruteraan Mekanikal, Universiti Teknikal Malaysia Melaka Hang Tuah Jaya, 76100, Durian Tunggal, \\ Melaka, Malaysia. \\ ${ }^{2}$ Advanced Manufacturing Center, Universiti Teknikal Malaysia Melaka, Hang Tuah Jaya, 76100 Durian Tunggal, \\ Melaka, Malaysia. E-mail: rizalalkahari@utem.edu.my \\ ${ }^{3}$ Center for Advanced Research on Energy, Universiti Teknikal Malaysia Melaka, Hang Tuah Jaya, 76100 Durian \\ Tunggal, Melaka, Malaysia. \\ ${ }^{4}$ Fakulti Teknologi Kejuruteraan Mekanikal dan Pembuatan, Universiti Teknikal Malaysia Melaka, Hang Tuah Jaya, \\ 76100, Durian Tunggal, Melaka, Malaysia. \\ ${ }^{5}$ Industrial Engineering Department, Fakulti Kejuruteraan, Universitas Bina Nusantara, Jakarta, 11430, Indonesia
}

High deposition rate with minimal heat input is one of the primary emphasis in wire arc additive manufacturing. This study aims to determine the optimal input parameters of micro plasma welding for singlelayer deposition. The stability of a single layer is crucial as it serves as the foundation to the multi-layers deposition in producing 3D additively manufactured structure. The study focuses on wire feeding speed, welding speed, and pulse and their interaction between the input and response variables. Based on the study, the regression equation between the three key parameters and the response using the BoxBehnken Design response surface methodology was proposed. The outcome demonstrates that the optimized sample deposition produces a smooth surface appearance with no apparent defects.

Keywords: additive manufacturing, 3D printing, wire arc additive manufacturing, micro plasma arc welding, response surface methodology

\section{Introduction}

Additive manufacturing (AM) is a revolutionary manufacturing technology that allows any part to be formed by depositing successive layers of material [1]. $\mathrm{AM}$ is used in various fields since it allows for flexible manufacturing and mass customisation techniques [2]. Due to their versatility, AM techniques are ideal for manufacturing individual or custom parts, short runs of parts, and one-off repair solutions. Unlike the subtractive method, AM creates components by layering material on top of the substrate according to a predetermined layer thickness [3, 4]. Metal additive manufacturing is a popular technique in which complex components can be manufactured [5]. Wire arc additive manufacturing (WAAM) is one of the metal AM technologies that enable the cost-effective production and new ways of manufacturing near net-shape metallic parts [6]. The WAAM process, which uses metal wire as a feedstock and arc welding as a heat source, is a potential technology for mass-producing thin-walled metal structures on a large scale. The remarkable advantages of WAAM include a high deposition rate, high material usage efficiency, and limitless build envelop.

In recent years, WAAM has garnered considerable research attention, yet it has seen minimal industrial applications. Numerous issues with geometric accuracy, poor surface consistency, layer unevenness, poor repeatability, and the need for post-processing to complete a part $[7,8]$. Over the last decade, extensive research has been conducted on process details such as forming precision, surface quality, microstructure, mechanical properties, and residual stress to improve quality and meet industrial needs [9]. Prior research indicates that the superiority of the parts is typically related to the WAAM process parameters such as welding voltage, welding current, travel speed, and wire feed speed [10-13]. Wang et al.[14] demonstrated that processing parameters had impacted the dimensional accuracy, microstructure, and mechanical properties of aluminium alloy components using GTAW based WAAM. Besides that, the quality of the manufacturing component depends primarily on the geometry of the single bead to prevent issues like excessive weld bead and insufficient bonding occur [15]. However, many input process parameters are time-consuming and in- 
fluenced by complex interaction among various process parameters, which cause challenges to the parametric selection combination [16]. Hence, optimizing the process parameters is crucial to achieving superior component quality and mechanical properties. Kumar and Maji [8] discussed optimizing the selection of parameters for near net shape deposition to minimize void and excess material in WAAM by the Genetic Algorithm. Bead geometry parameters, width, height, and cross-section were expressed in process parameters like voltage, wire feed rate, torch speed, and gas flow rate. Ma et al.[7] investigated optimization strategies for manufacturing large and high thin-walled metallic structures with the robotic system. As a result, the selected combination strategies can improve the surface flatness of layers, reducing the differences in the heights of layers. Other researchers, Sarathchandra et al.[17] optimized single-layer deposition parameters to ensure the desired mechanical properties using RSM methods and successfully deposited single clad bead using cold metal transfer process. Unfortunately, most previous research has relied on traditional process variations such as gas metal arc welding (GMAW), gas tungsten arc welding (GTAW), and plasma arc welding (PAW) that produce a heat input of up to $1114 \mathrm{~J} / \mathrm{mm}$ [18]. Thus, the impact of heat input on the macrostructure sample formed by the WAAM process resulting severe thermal damage due to the remelted area of previously deposited layers [18, 19]. The extensive heat input, according to Xiong et al.[20], could cause a molten pool overflow and significantly reducing the built parts deposition and quality.

Therefore, the present works employ a WAAM process based on micro-plasma arc welding (MPAW) to study thermal heat input and creates single-layer geometry by utilizing response surface methodology (RSM). Single layer geometry is crucial as it serves as the basis of additively manufactured component. The wire feed speed $(f)$, welding speed $(v)$, and pulse $(p)$ are taken as input parameters, while the single weld bead width, height, and surface roughness as output response variables. The experiment was designed and carried out using the Box-Behnken RSM technique to find the optimal process parameters [21]. The main objectives of this study are to: (i) determine the optimization of input process parameters by considering the maximum bead width, maximum bead height, and minimum surface roughness as a response variable, (ii) evaluate their effect and interaction of the selected parameter on the resulting properties, and (iii) develop an empirical model for predicting the influence of selected parameter on surface quality.

\section{Experimental procedure}

\subsection{Material and sample preparation}

In this study, standard stainless steel SS316L was used as the filler wire with a diameter of $1.2 \mathrm{~mm}$ and a 304 stainless steel plate with $150 \times 15$ × 6 mm dimensions as the substrate platform. Before deposition, the substrate surface was sandblasted to eliminate any surface contamination. The experiment was performed using EWM 25 micro plasma arc welding as a heat source, connected to a 3D printer [22], and operated automatically by the Mach3 controller. The use of an on-off switch to automatically control the wire feed system in direct sync with the arc welding and motion systems. In addition, 92.5\% argon $+7.5 \%$ hydrogen used as a shielding gas. Fig. 1 depicts the schematic setup of wire feeding geometry and the MPAW torch. The trial runs were carried out to determine the operating ranges of all selected factors by varying one factor while maintaining the others constant. The operating ranges are determined by assessing the welding process for a smooth appearance and the absence of apparent flaws such as porosity and undercut. The wire feeding angle was set at $60^{\circ}$, the arc length, $\mathrm{L}$, is $8.5 \mathrm{~mm}$, and $\mathrm{h}$ is approximately $1 \mathrm{~mm}$ less than $\mathrm{L}$ to obtain a smooth metal transfer of wire. The single weld bead was deposited with $100 \mathrm{~mm}$ length to determine the optimal process parameter and evaluate the relationship between input parameters and the response variable.

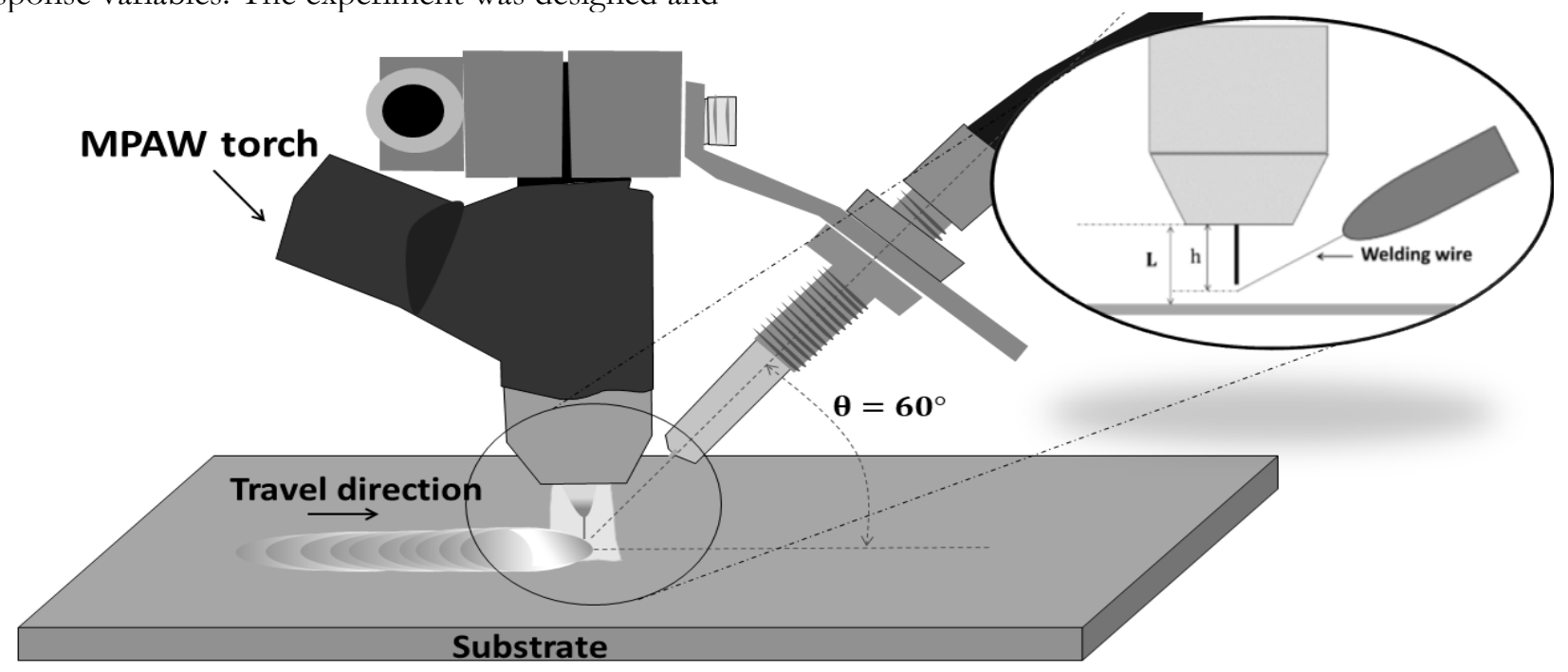

Fig. 1 Schematic of MPAW based WAAM technique wire feed geometry 


\subsection{Experimental Design}

The correlation between input parameters and weld bead geometry was established through the RSM method. The RSM method was used to model, evaluate, and optimize a multi-factor response problem through appropriately structured experiments and optimize objectives. Additionally, the technique represents the non-linear relationship between the input and response variables [23]. A box Behnken design was employed in this study to minimize the number of experiments and to determine the interaction between the specified factor combination. The total number of an experiment is 17 , where the number of factors was
3 , and the centre point was 5 . Based on response surface design the predicted response of bead width (W), bead height $(\mathrm{H})$, and surface roughness $(\mathrm{Ra})$ for different factor settings wire feed speed (f), welding speed $(v)$, and pulse (p) was determined. Next, the interaction is explained by plotting the relationship between the factor and the response and finding the setting that optimises one or more responses. Three major process parameters were chosen as input variables: wire feed speed, travel speed, and pulse. Level variation to the input parameters was applied (low, -1 ; medium, 0 ; and high 1). Tab. 1 shows the operating range to ensure the quality of the deposited single weld bead.

Tab. 1 Ranges and levels of parameters

\begin{tabular}{cccccc}
\hline Parameters & Units & Notations & \multicolumn{3}{c}{ Levels } \\
\cline { 3 - 6 } & & & -1 & 0 & 1 \\
\hline Welding speed & $\mathrm{mm} / \mathrm{min}$ & $v$ & 35.0 & 37.5 & 40.0 \\
Wire feed speed & $\mathrm{cm} / \mathrm{min}$ & $f$ & 60.0 & 63.0 & 66.0 \\
Pulse & $\%$ & $p$ & 90.0 & 95.0 & 100.0 \\
\hline
\end{tabular}

\section{Results and Discussion}

Fig. 2 illustrates the successful deposition of a single layer of stainless-steel SS 316L using the MPAWbased WAAM process. First, the geometrical properties of $\mathrm{W}$ and $\mathrm{H}$ were measured using a digital vernier calliper at four distinct locations $20 \mathrm{~mm}$ apart and repeated three times to assure accuracy before taking the average value. The surface roughness of a single weld bead was then assessed using a 3D profilometer at four different points on the top surface.
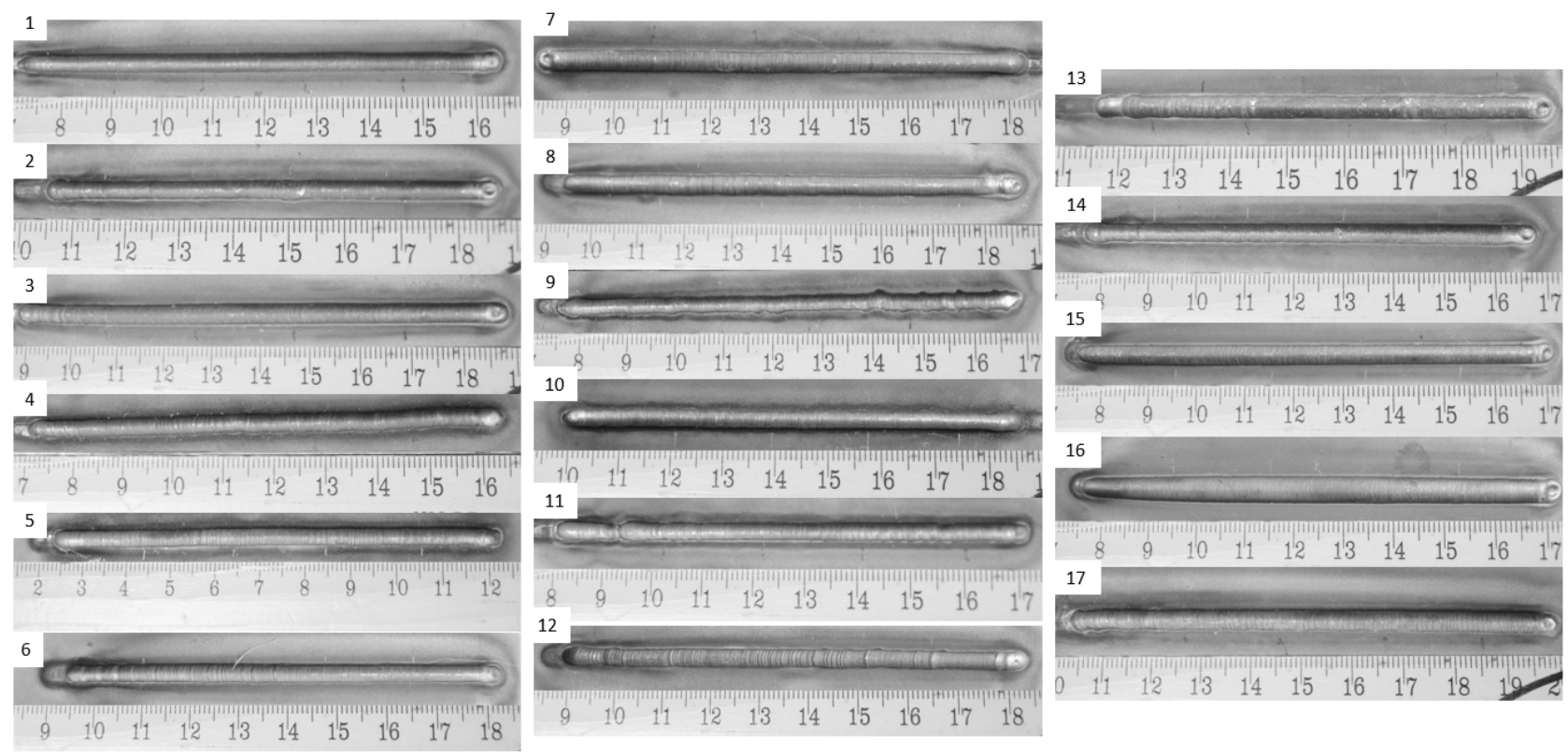

Fig. 2 Fabricated sample single weld bead deposition

Tab. 2 shows the results of the experiments. Seventeen test experiments were performed with process parameters from the design matrix set that was selected at random. The input and response values were determined by design expert statistical software. Three quadratic regressing equations were obtained using the response surface method for $\mathrm{W}, \mathrm{H}$, and $\mathrm{Ra}$ and expressed in Eq. 1, 2, and 3, respectively. Analysis of variance (ANOVA) was used to validate the models and determine the significance of the process parameters identified in Tab. 3Chyba! Nenalezen zdroj odkazů. As shown in Tab. 3, the p-value for each model is 0.05 , indicating that the model terms are statistically significant. The $\mathrm{F}$ ratio is greater than the tabulated values at the $95 \%$ confidence level. The coefficient of determination (R2) of the built models was 0.9884 , 
0.9639 , and 0.9455 for $\mathrm{W}, \mathrm{H}$, and $\mathrm{Ra}$, respectively (close to the ideal value of 1.0). R2 values demonstrated that the models capable of making further predictions. The linear welding speed is the most significant factor contributing $35.98 \%$ to the bead width. Moreover, the linear wire feed speed is the most significant factor for bead height, with $39.17 \%$ of the contribution to the response. For surface roughness, the quadratic welding speed contributes the highest significant factor on response with $22.60 \%$.

Tab. 2 Input and response variable of BBD response surface methodology

\begin{tabular}{ccccccc}
\hline Run & $f(\mathrm{~cm} / \mathrm{min})$ & $v(\mathrm{~mm} / \mathrm{min})$ & $p(\%)$ & $\mathrm{W}(\mathrm{mm})$ & $\mathrm{H}(\mathrm{mm})$ & $\mathrm{Ra}(\mu \mathrm{m})$ \\
\hline 1 & 60 & 35.0 & 95 & 3.913 & 2.138 & 2.208 \\
2 & 66 & 37.5 & 90 & 3.600 & 2.750 & 2.350 \\
3 & 66 & 37.5 & 100 & 4.025 & 2.500 & 3.021 \\
4 & 63 & 35.0 & 90 & 4.498 & 1.913 & 2.077 \\
5 & 63 & 37.5 & 95 & 3.863 & 2.075 & 2.113 \\
6 & 66 & 40.0 & 95 & 3.738 & 2.513 & 3.769 \\
7 & 63 & 37.5 & 95 & 3.800 & 2.125 & 2.546 \\
8 & 63 & 35.0 & 100 & 5.325 & 1.788 & 1.930 \\
9 & 60 & 37.5 & 100 & 4.075 & 2.125 & 2.079 \\
10 & 60 & 37.5 & 90 & 3.600 & 2.213 & 1.473 \\
11 & 63 & 37.5 & 95 & 3.863 & 2.150 & 2.231 \\
12 & 63 & 40.0 & 100 & 3.988 & 1.926 & 2.685 \\
13 & 60 & 40.0 & 95 & 3.488 & 2.025 & 3.902 \\
14 & 63 & 37.5 & 95 & 3.825 & 2.150 & 2.107 \\
15 & 63 & 37.5 & 95 & 3.813 & 2.250 & 2.119 \\
16 & 63 & 40.0 & 90 & 3.525 & 2.050 & 2.894 \\
17 & 66 & 35.0 & 95 & 3.925 & 2.513 & 4.069 \\
\hline
\end{tabular}

$W=-2788.81688+92.93927 f+72.17225 v-1.74938 p-0.739271 f^{2}+0.035350 v^{2}$

$+0.011213 p^{2}+0.018861 f^{2} v-2.36858 f^{*} v-0.000833 f^{*} p-0.07300 v^{*} p$

$$
\begin{gathered}
H=68.08750-4.18438 f+1.75938 v+0.654687 p+0.034722 f^{2}-0.026500 v^{2}-0.002625 p^{2} \\
+0.003750 f^{*} v-0.002708 f^{*} p+7.56647 e^{-17} v^{*} p \\
R a=37.87197-5.15064 f-4.12793 v+4.11505 p+0.061017 f^{2} \\
+0.114382 v^{2}-0.021655 p^{2}-0.066461 f^{*} v ;+0.001079 f^{*} p-0.001213 v^{*}
\end{gathered}
$$

Where:

W....Width [mm],

H...Height [mm],

Ra...Roughness [ $\mu \mathrm{m}]$,

$f$...Wire feed speed $[\mathrm{mm} / \mathrm{s}]$

$v$...Welding speed $[\mathrm{mm} / \mathrm{s}]$

$p$...Pulse $[\%]$
Fig. 3 depicts a scatter plot of the actual and predicted values of the three responses used to verify the models. Scatter plots are a statistical method for determining the relationship between two random variables. The diagonal line represents the point at which the observed and predicted values are identical. Fig. $3(\mathrm{a})$ - (c) shows that the predicted values match the diagonal line well, and the built final model fits almost perfectly. 
Tab. 3 ANOV A table for (a) bead width, $W$, (b) bead height, $H$, (c) bead roughness, $R a$

\begin{tabular}{|c|c|c|c|c|c|c|c|}
\hline Source & $\mathrm{DF}$ & Adj SS & Adj MS & F-value & p-value & $\begin{array}{c}\text { Contribu- } \\
\text { tion }(\%)\end{array}$ & $\mathrm{R}^{2}$ \\
\hline (a) Model & 10 & 2.9300 & 0.2933 & 50.95 & 0.0001 & & 0.9884 \\
\hline$f$ & 1 & 0.0056 & 0.0056 & 0.9807 & 0.3603 & 0.19 & \\
\hline$v$ & 1 & 1.3300 & 1.330 & 231.79 & 0.0001 & 35.98 & \\
\hline$p$ & 1 & 0.5995 & 0.5995 & 104.17 & 0.0001 & 20.20 & \\
\hline$f^{*} v$ & 1 & 0.0141 & 0.0141 & 2.450 & 0.1685 & 0.48 & \\
\hline$f^{*} p$ & 1 & 0.0006 & 0.0006 & 0.1086 & 0.7529 & 0.02 & \\
\hline$v^{*} p$ & 1 & 0.0333 & 0.0333 & 5.7900 & 0.0529 & 1.12 & \\
\hline$f^{2}$ & 1 & 0.3488 & 0.3488 & 60.60 & 0.0002 & 9.65 & \\
\hline$v^{2}$ & 1 & 0.2055 & 0.2055 & 35.71 & 0.0010 & 7.90 & \\
\hline$p^{2}$ & 1 & 0.3308 & 0.3308 & 57.48 & 0.0003 & 11.15 & \\
\hline$f^{2} v$ & 1 & 0.3602 & 0.3602 & 62.58 & 0.0002 & 12.14 & \\
\hline Residual & 6 & 0.0345 & 0.0058 & & & & \\
\hline Error & & & & & & 1.16 & \\
\hline Lack of Fit & 2 & 0.0312 & 0.0156 & 18.85 & 0.0092 & 1.05 & \\
\hline Pure Error & 4 & 0.0033 & 0.0008 & & & 0.11 & \\
\hline Cor Total & 16 & 2.9700 & & & & 100.00 & \\
\hline (b) Model & 9 & 0.9692 & 0.1077 & 20.77 & 0.0003 & & 0.9639 \\
\hline$f$ & 1 & 0.3938 & 0.3938 & 75.97 & 0.0001 & 39.17 & \\
\hline$v$ & 1 & 0.0033 & 0.0033 & 0.6367 & 0.4511 & 0.330 & \\
\hline$p$ & 1 & 0.0431 & 0.0431 & 8.32 & 0.0235 & 4.290 & \\
\hline$f^{*} v$ & 1 & 0.0032 & 0.0032 & 0.6103 & 0.4603 & 0.310 & \\
\hline$f^{*} p$ & 1 & 0.0066 & 0.0066 & 1.27 & 0.2963 & 0.660 & \\
\hline$v^{*} p$ & 1 & 0.0000 & 0.0000 & 0.0000 & 1.0000 & 0.000 & \\
\hline$f^{2}$ & 1 & 0.4112 & 0.4112 & 79.32 & 0.0001 & 37.82 & \\
\hline$v^{2}$ & 1 & 0.1155 & 0.1155 & 22.28 & 0.0022 & 12.00 & \\
\hline$p^{2}$ & 1 & 0.0181 & 0.0181 & 3.50 & 0.1036 & 1.800 & \\
\hline Residual & 7 & 0.0363 & 0.0052 & & & & \\
\hline Error & & & & & & 3.610 & \\
\hline Lack of Fit & 3 & 0.0200 & 0.0067 & 1.64 & 0.3140 & 1.990 & \\
\hline Pure Error & 4 & 0.0162 & 0.0041 & & & 1.620 & \\
\hline Cor Total & 16 & 1.01 & & & & 100.00 & \\
\hline (c) Model Ra & 9 & 8.32 & 0.9245 & 13.50 & 0.0012 & & 0.9455 \\
\hline$f$ & 1 & 1.57 & 1.57 & 22.95 & 0.0020 & 17.87 & \\
\hline$v$ & 1 & 1.10 & 1.10 & 16.07 & 0.0051 & 12.51 & \\
\hline$p$ & 1 & 0.1059 & 0.1059 & 1.55 & 0.2538 & 1.20 & \\
\hline$f^{*} v$ & 1 & 0.9938 & 0.9938 & 14.51 & 0.0066 & 11.29 & \\
\hline$f^{*} p$ & 1 & 0.0010 & 0.0010 & 0.0153 & 0.9050 & 0.01 & \\
\hline$v^{*} p$ & 1 & 0.0009 & 0.0009 & 0.0134 & 0.9110 & 0.01 & \\
\hline$f^{2}$ & 1 & 1.27 & 1.27 & 18.54 & 0.0035 & 15.03 & \\
\hline$v^{2}$ & 1 & 2.15 & 2.15 & 31.41 & 0.0008 & 22.60 & \\
\hline$p^{2}$ & 1 & 1.23 & 1.23 & 18.01 & 0.0038 & 14.02 & \\
\hline Residual & 7 & 0.4795 & 0.0685 & & & & \\
\hline Error & & & & & & 5.45 & \\
\hline Lack of Fit & 3 & 0.3385 & 0.1128 & 3.20 & 0.1452 & 3.85 & \\
\hline Pure Error & 4 & 0.1410 & 0.0352 & & & 1.60 & \\
\hline Cor Total & 16 & 8.80 & & & & 100.00 & \\
\hline
\end{tabular}




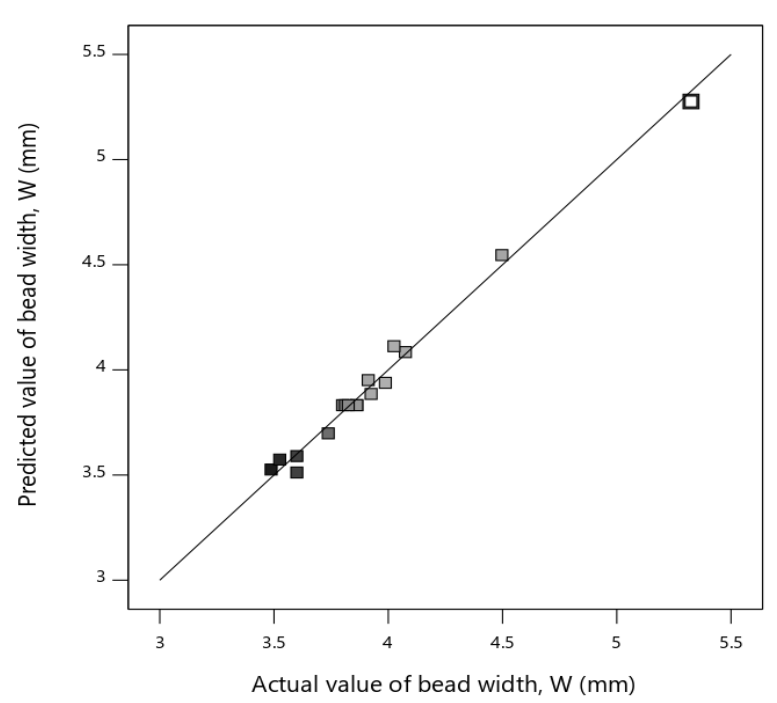

(a)

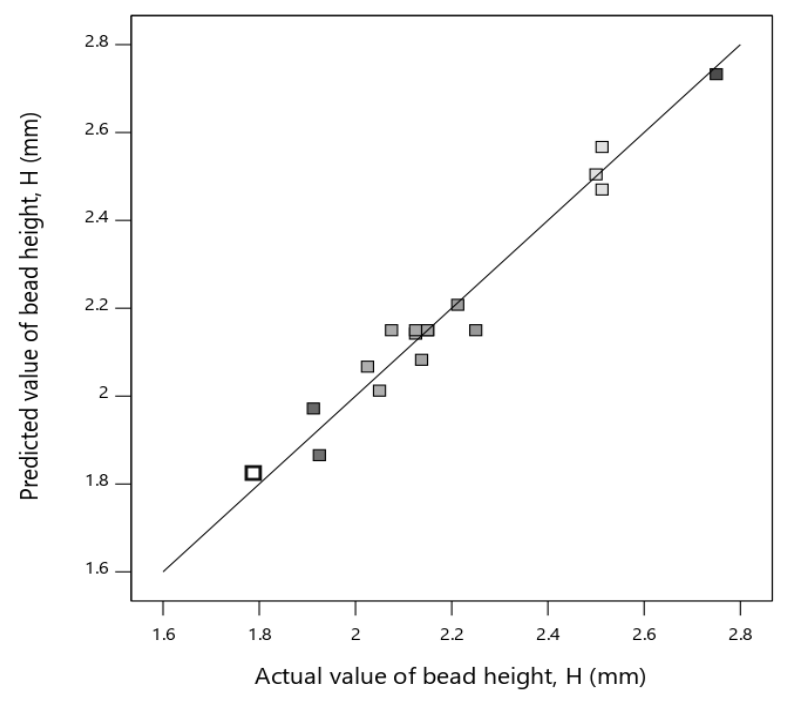

(b)

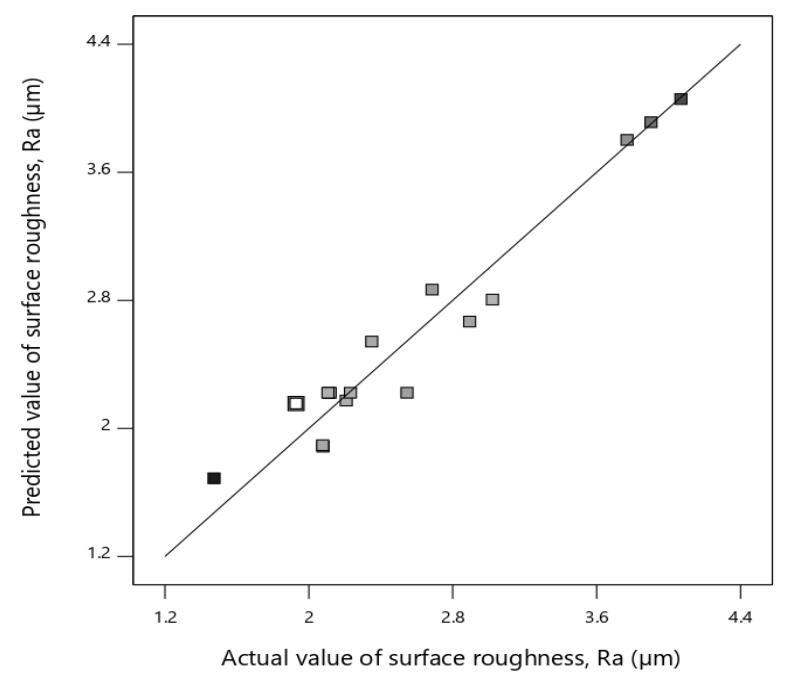

(c)

Fig. 3 Predicted versus actual graph of weld bead (a) width, (b) height and (c) surface roughness
Fig. 4 (a) - (c) shows the modelled and measured bead width, bead height, and surface roughness to validate the above-developed models. Again, the result of the scatter plot graph shows the modelled and measured plotted almost similar.

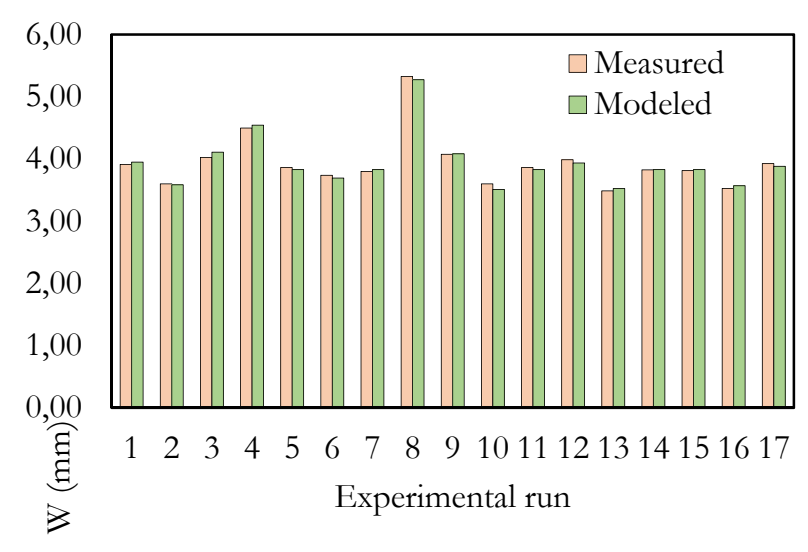

(a)

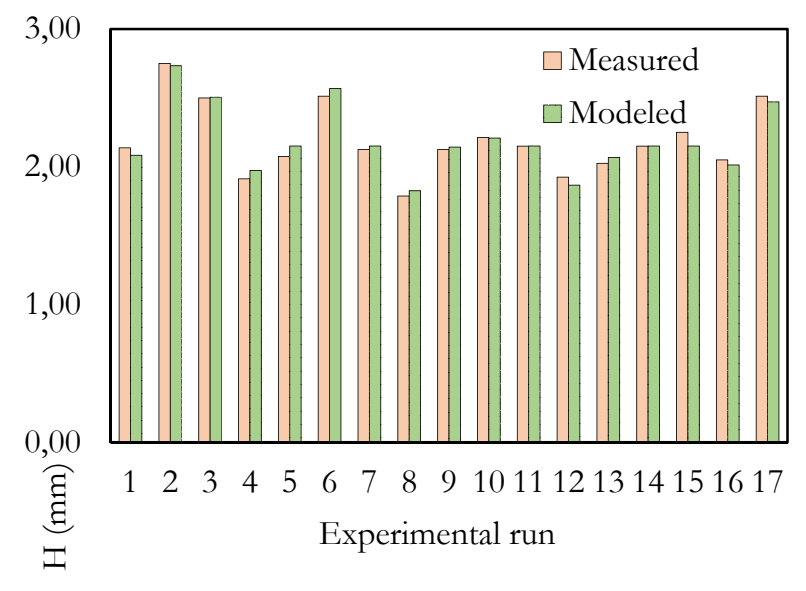

(b)

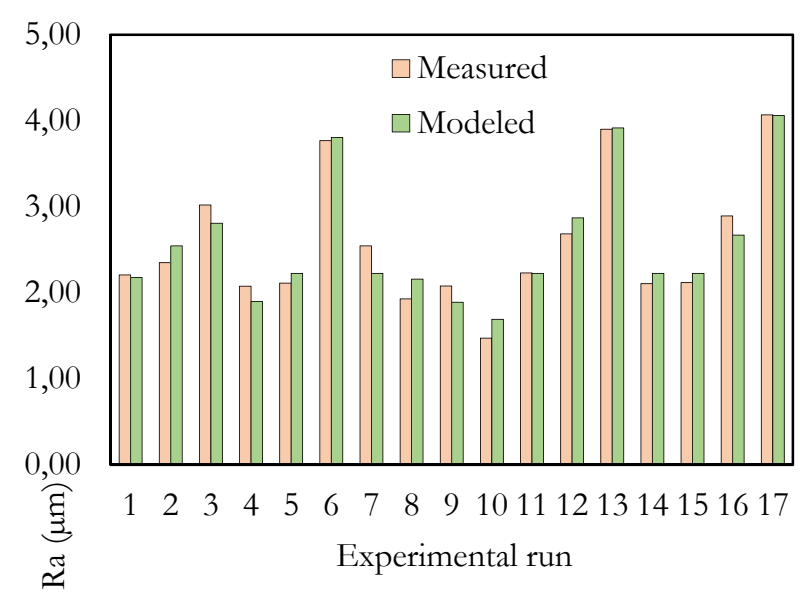

(c)

Fig. 4 Comparison between the modeled value and measured value of; (a) bead height, (b) bead width, and (c) surface roughness 


\subsection{Effect of input parameters on the response variable}

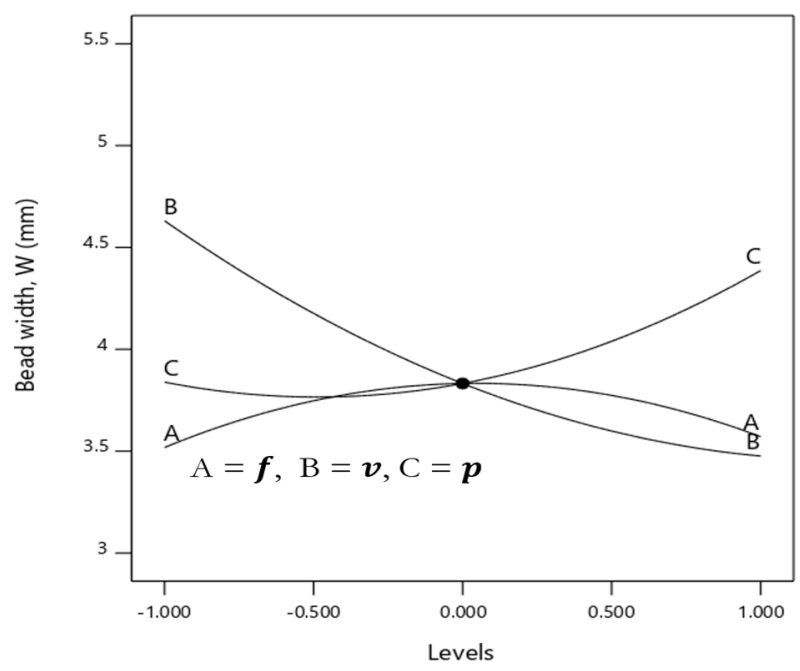

(a)

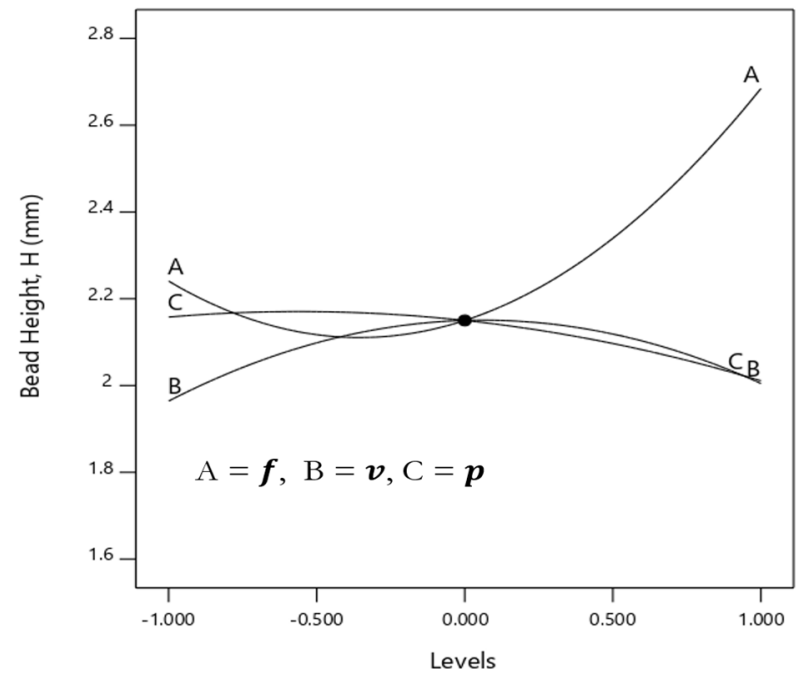

(b)

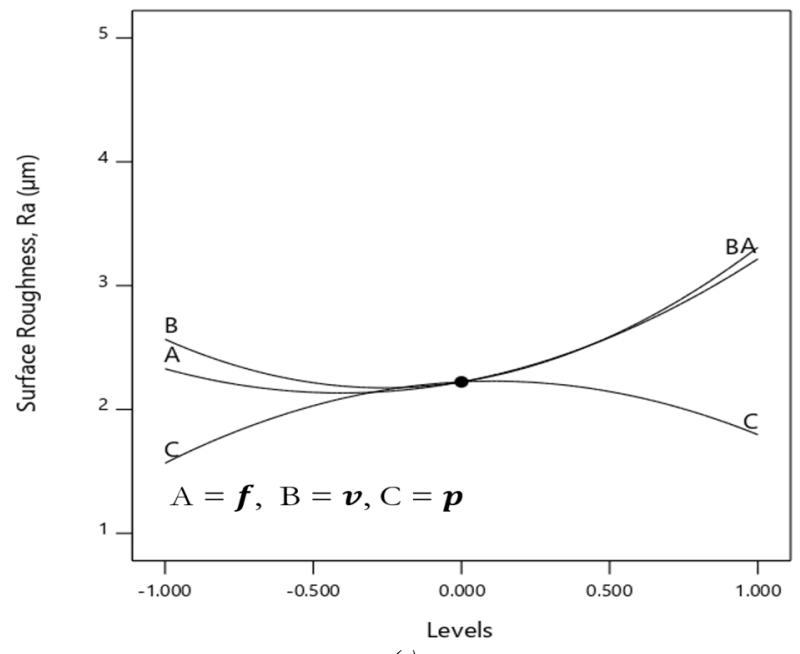

(c)

Fig. 5 Effect of input parameters on a response variable (a) bead width, (b) bead height, and (c) surface roughness
The effects of input parameters on $\mathrm{W}, \mathrm{H}$, and $\mathrm{Ra}$ were calculated and presented based on the final model that has been developed, as shown in Fig. 5(a), (b), and (c). During the entire deposition process, all other process parameters were kept constant. Fig. 5(a) shows that $v$ has the most significant influence on $\mathrm{W}$. The lower the $v$, the wider the $\mathrm{W}$ produced. The combination of the lowest $p$ and $f$ with the slow welding speed resulted in higher heat input and, as a result, a larger melt pool dimension produced [24, 25]. Fig. 5(b) demonstrates that increasing the wire feed speed, $f$ increases the weld bead height. It shows that $f$ has the most significant influence on bead height, $\mathrm{H}$. As the wire feed increase, more wire enters the molten pool, and the volume of metal melted rises with the same heat input [26]. As a result, the viscosity and surface tension increase, diminishing the weld pool's ability to flow in width but gradually building in height. Fig. 5(c) shows that the combination of higher wire feed speed and welding speed leads to an increased surface roughness of the single-layer weld bead. When the $f$ and $v$ values increase, the phenomenon of mixed layers in a particular area occurs, indicating that the molten pool is unstable during deposition. According to $\mathrm{Wu}$ et al. [27], the molten pool becomes unstable, and the arc force impacts the developing weld bead and formed low-quality weld bead.

\subsection{Interaction effect of input parameters on a re- sponse variable}

The contour plot visually shows the interaction effect of the input parameters on the response, as shown in Fig. 6, Fig. 7, and Fig. 8. These contour plots illustrate in detail the impact on the response variable in Z-axis towards two input variables. The input parameters varied while maintaining the remains at zero levels, as shown in Fig. 6 depicts the interactions of the $f, v$, and $p$ on bead width, W. The result shows that higher heat input increases the bead width as $p$ increases and $v$ decreases.

Fig. 7 illustrates the interaction effect of $f, v$, and $p$ on $\mathrm{H}$ using a contour map. The input parameters indicate that wire feeding speed, $f$ has the most significant effect on bead height. Fig. 7(a) and Fig. 7(b) depicts when the $\mathrm{f}$ increases, the bead height increase. Fig. 7(c) shows that the contour graph is quadratic where the bead height varies significantly on $v$, and $p$. The contribution rate of $v$ and $p$ is $0.00 \%$ onto bead height as tabulated in the ANOVA table. The welding speed and pulse effect are closely related to thermal behaviour and weld bead shape of width. Wang et al. [28] also investigated the different current used in VPGTAW and their effect on weld bead width and solidification characteristics. Based on the observation, the change in bead height is not significant with a change in welding speed. 


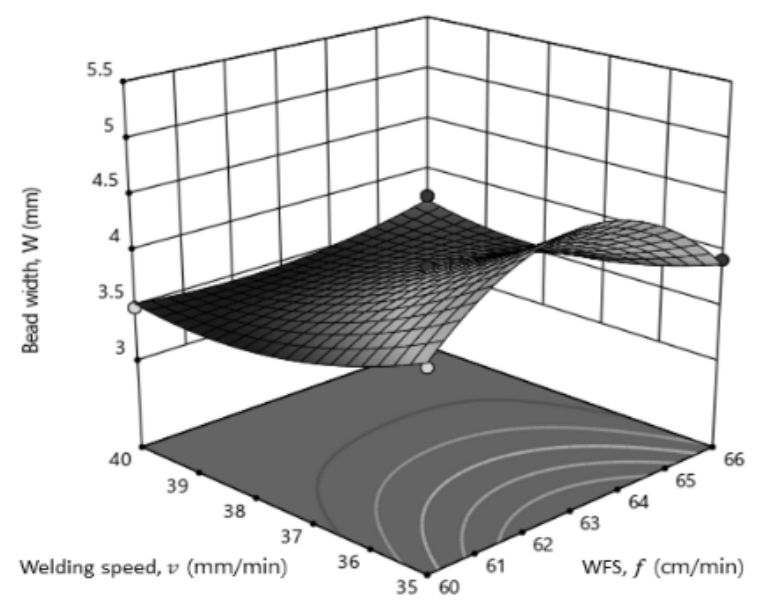

(a)

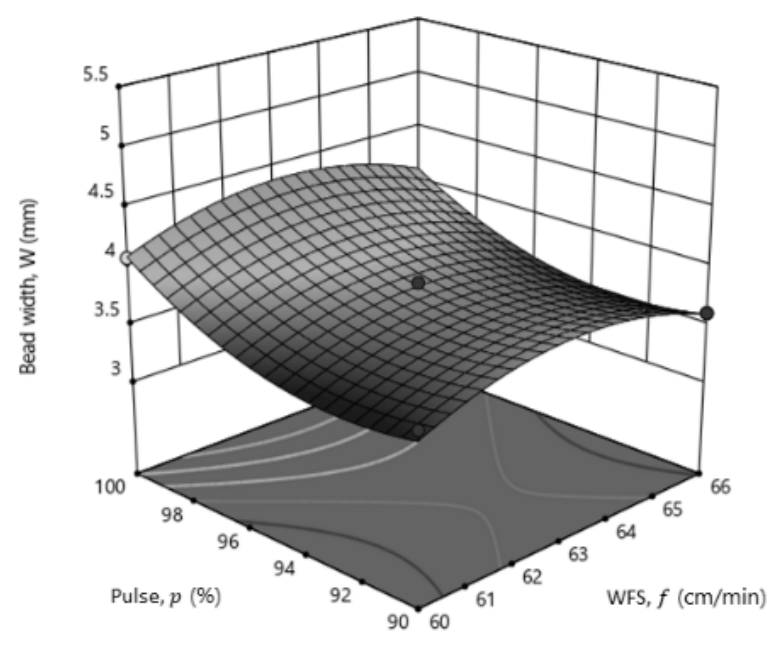

(b)

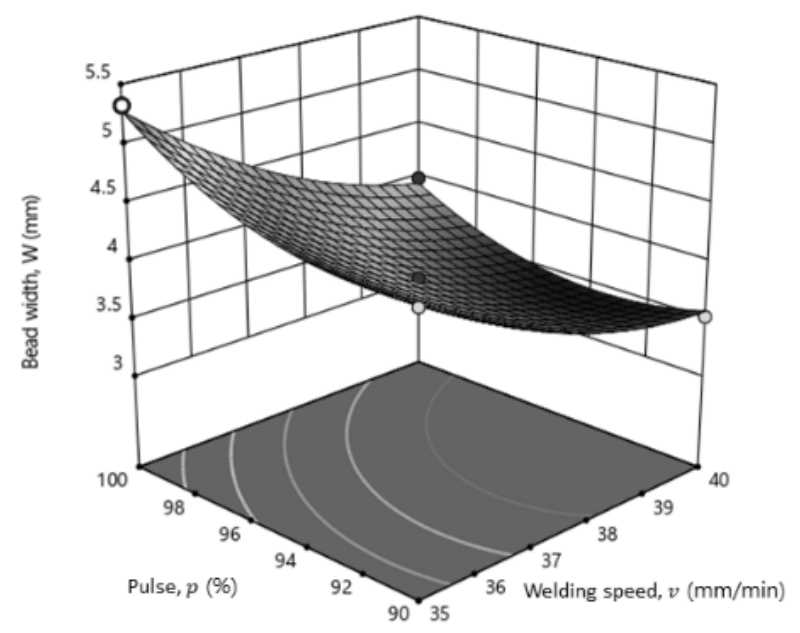

(c)

Fig. 6 Contour plots illustrating the cumulative effects of the input variables on the bead width, $W$

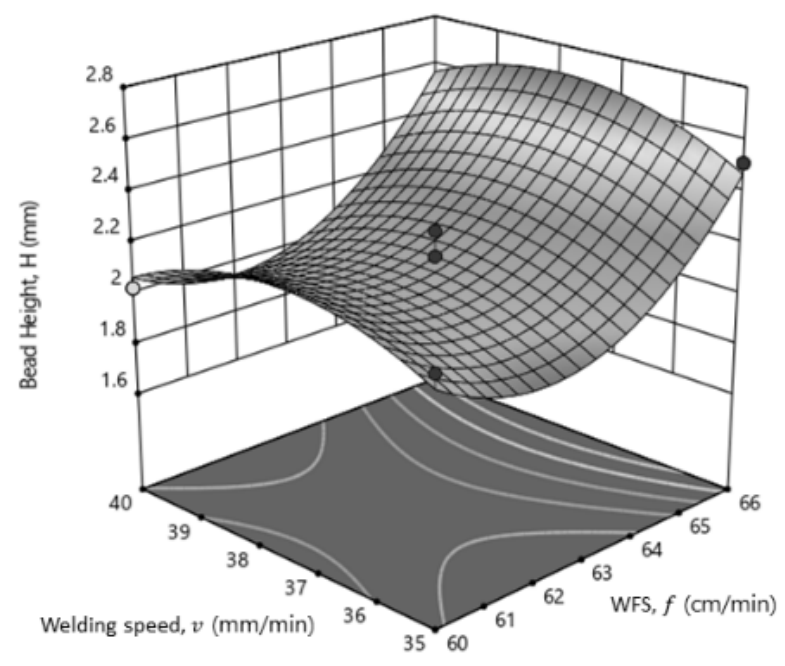

(a)

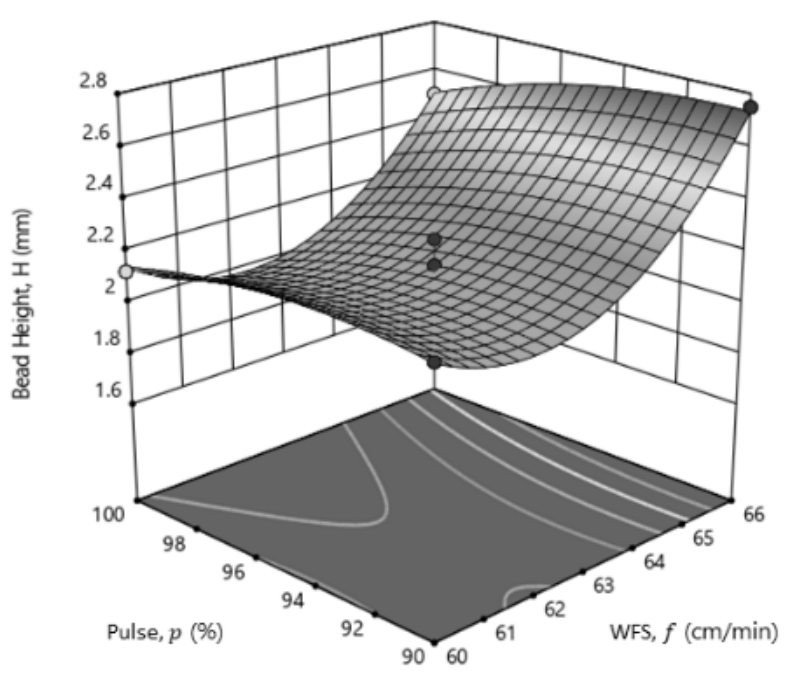

(b)

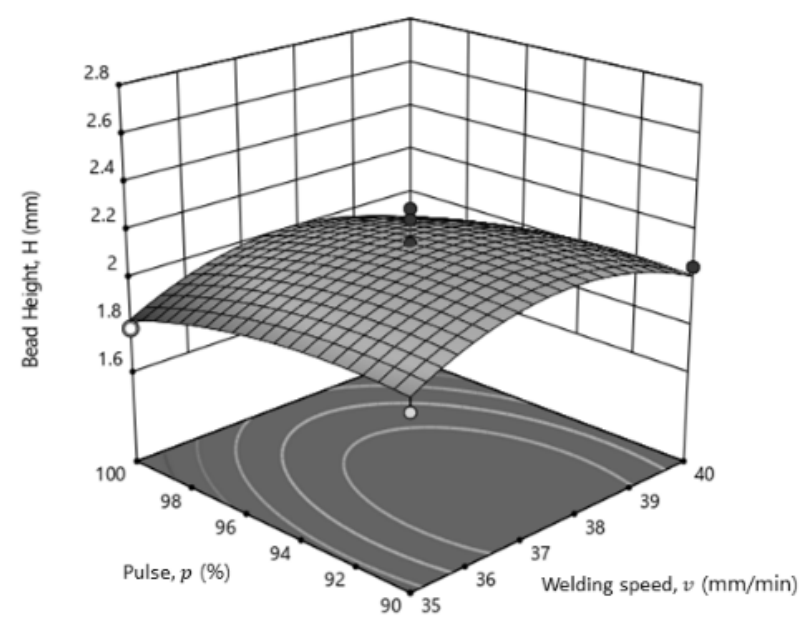

(c)

Fig. 7 Contour plots illustrating the cumulative effects of the input variables on the bead height, $H$ 
Fig. 8 shows the influence of $f, v$, and $p$ on surface roughness, Ra. The increase in $f$ and $v$ favours increasing the Ra, as shown in Fig. 8 (a). When both input parameters increase, a large amount of heat is generated, which affects the surface. Under lower heat input, the weld bead has a smoother surface and a better appearance. The graph in Fig. 8(b) and Fig. 8(c) shows that surface roughness is not significantly affected with pulse and wire feed speed and between pulse and welding speed. The quadratic welding speed, $v$ recorded the most influential parameter on $\mathrm{Ra}$ with the highest contribution rate of $22.6 \%$.

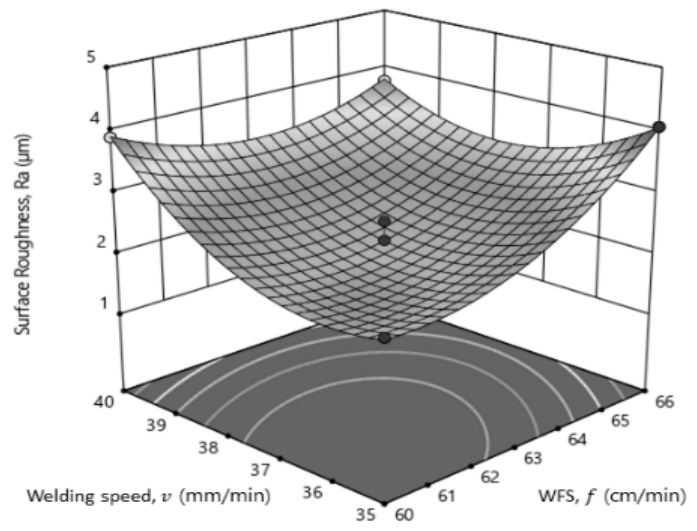

(a)

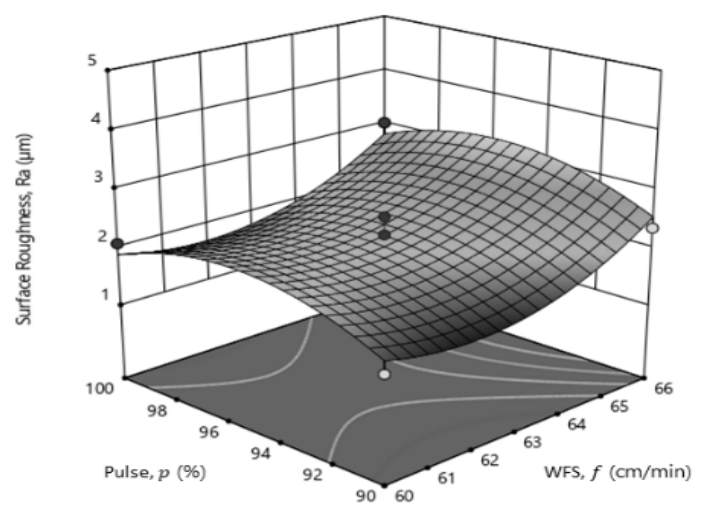

(b)

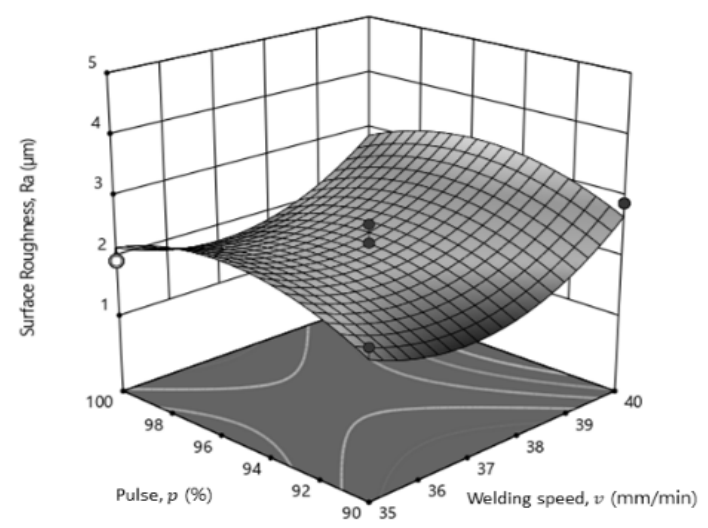

(c)

Fig. 8 Contour plots illustrating the cumulative effects of the input variables on the surface roughness, $\mathrm{Ra}$

\subsection{Optimisation of bead width, bead height, and surface roughness}

The RSM -based desirability approach was used to obtain the optimization parameters. The prediction of the first layer is critical to ensure the entire 3D metal parts is manufacturable. In this study, the optimal response condition was determined by maximizing bead width, maximizing bead height, and minimizing surface roughness. As proposed by Corradi et al. [29], in order to ensure manufacturing stability, it is essential to achieve high deposition efficiency and producing a higher wall with fewer layers. According to Saratchandra et al. [17], the optimal conditions for AM are minimum penetration and dilution with maximum height and width. Fig. 9 depicts the optimal response values and the corresponding input parameter values. The optimum wire feed speed, welding speed, and pulse parameters are $64.8568 \mathrm{~cm} / \mathrm{min}, 35.6254 \mathrm{~mm} / \mathrm{min}$, and $100 \%$, respectively. The optimal response values for bead width, bead height, and surface roughness are $4.47627 \mathrm{~mm}, 2.20936 \mathrm{~mm}$, and $2.3623 \mu \mathrm{m}$ respectively.
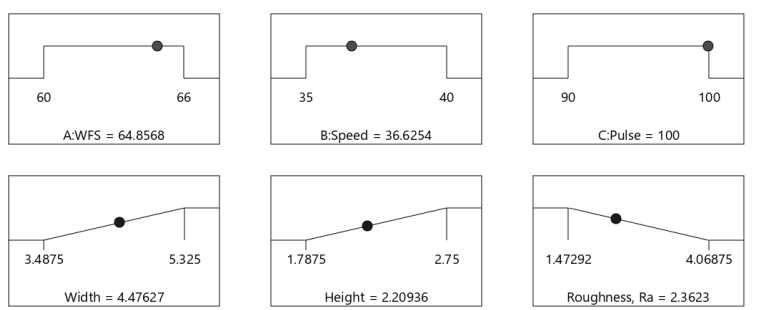

Fig. 9 Numerical optimization ramps of input parameter and response variable

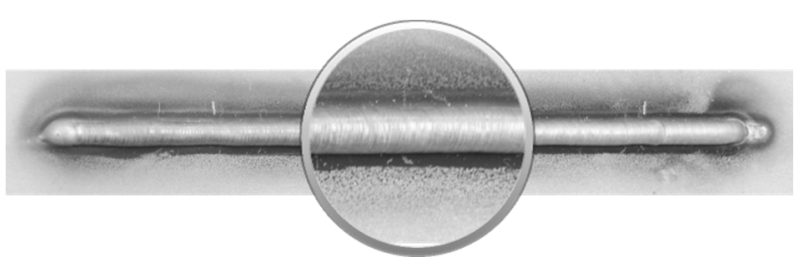

Fig. 10 Single layer deposition result with optimized parameters

The predicted responses have a desirability of 0.537 . The optimal bead setting of input parameters was obtained from the response optimization. A confirmation experiment has been conducted by manufacturing single-layer deposition utilizing the optimal setting of the process parameters, as shown in Fig. 10. Tab. 4 shows the theoretical and experimental values of the ideal single layers with percentage area. However, the percentage error of width is a little higher with $11.476 \%$. The data collected above shows that the welding speed dramatically influences the bead width. Under the influence of the welding speed factor, the flow of molten metal in the weld pool becomes violent and fluctuates irregularly [30]. The amount of volume 
of the molten metal pool must be suitable because the molten metal within the melt pool tends to flow out if the volume is too large and may contribute to the existence of hump if the volume is too small. Therefore, an adequate range of pool volumes required for consistent deposition bead width.

$$
\text { Error }(\%)=\frac{\text { Measured value }- \text { Predicted value }}{\text { Predicted value }} \times 100
$$

Tab. 4 Confirmation experiment results

\begin{tabular}{cccc}
\hline Responses & Experimental value & Predicted value & Error (\%) \\
\hline Bead width, W (mm) & 3.9625 & 4.4762 & 11.476 \\
Bead height, H (mm) & 2.2875 & 2.2094 & 3.5349 \\
Surface roughness, $\mathbf{R a}(\boldsymbol{\mu m})$ & 2.3000 & 2.3623 & 2.6373 \\
\hline
\end{tabular}

As a result, the multi-layer deposited on the substrate using microplasma WAAM technology based on the input parameters obtained from the above optimization is depicted in Fig. 11. The forming appearance of a multi-layer sample is quite excellent with a smooth surface, no spatter, distortion, and no noticeable defects such as porosity and undercut.

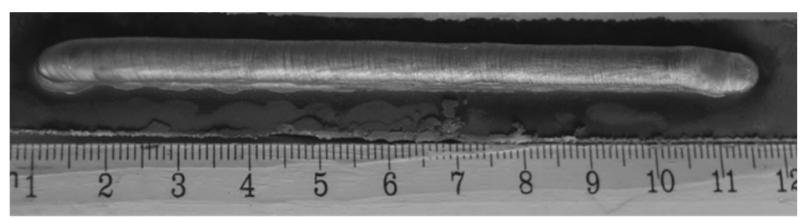

(a)

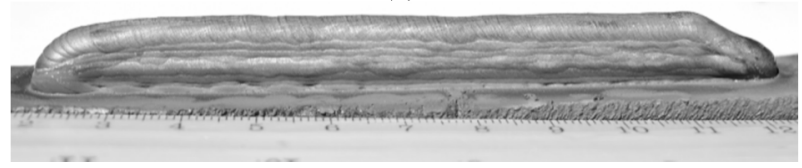

(b)

Fig. 11 Multi-layer deposition result with optimized parameters, (a) Top view, (b) front view

\section{Conclusion}

This study used the RSM technique with the Box Behnken method to evaluate the effect and interaction of input parameters and response variables, determine the optimal input parameter, and develop empirical models. The following is the inference drawn from the findings based on the method and evaluation made:

- The combination of random input parameters using the RSM approach successfully generates 17 continuous single-layer depositions.

- The regression equation between the input parameters (wire feed speed, welding speed, and pulse) and the response variables (bead width, bead height, and surface roughness) established using the RSM method. The model and measured value were found to be in good agreement and suitable for evaluation in future research.

- $\quad$ The welding speed, $v$, has the most influence on bead width, W, and surface roughness, Ra.
The input parameters of wire feed speed, $f$, influence bead height, $\mathrm{H}$.

- The optimum wire feed speed, welding speed, and pulse parameters were $64.8568 \mathrm{~cm} / \mathrm{min}$, $35.6254 \mathrm{~mm} / \mathrm{min}$, and $100 \%$, respectively. Thus, the outcome demonstrates that the single layer generated by the optimal parameter was applicable and preferable. Furthermore, the percentage error between experimental and expected values is minimal.

\section{Acknowledgement \\ The authors acknowledge the financial support from Zamalah Scheme, Universiti Teknikal Malaysia Melaka.}

\section{References}

[1] PERNICA, J. SUSTR, M., DOSTAL, P., BRABEC, M., \& DOBROCKY, D. (2021). Tensile Testing of 3D Printed Materials Made by Different Temperature. Manufacturing Technology, Vol. 21, No. 3, pp. 398-404. doi: 10.21062/mft.2021.039.

[2] SRINIVAS, M., \& BABU, B. S. (2017). A Critical Review on Recent Research Methodologies in Additive Manufacturing. Materials Today: Proceedings, Vol. 4, No. 8, pp. 9049-9059. doi: 10.1016/j.matpr.2017.07.258.

[3] ELKASEER, A., SCHNEIDER, S., \& SCHOLZ, S. G. (2020). Experiment-Based Process Modeling and Optimization for HighQuality and Resource-Efficient FFF 3D Printing. Applied Sciences, Vol. 10, No. 8, pp. 2899. doi:10.3390/app10082899.

[4] HADEN, C. V., ZENG, G., CARTER, F. M., RUHL, C., KRICK, B. A., \& HARLOW, D. G. (2017). Wire and arc additive manufactured steel: Tensile and wear properties. Additive Manufacturing, Vol. 16. No. 2010, pp. 115-123. doi: 10.1016/j.addma.2017.05.010. 
[5] HANZL, P., \& ZETKOVÁ, I. (2019). Benefits of a New Approach to Designing Milling Cutter Using Metal Additive Manufacturing. Manufacturing Technology, Vol. 19, No. 3, pp. 385-390. doi: 10.21062/ ujep/301.2019/a/12132489/MT/19/3/385.

[6] ORTEGA, A. G., CORONA GALVAN, L., SALEM, M., MOUSSAOUI, K., SEGONDS, S., ROUQUETTE, S., \& DESCHAUXBEAUME, F. (2019). Characterisation of 4043 aluminium alloy deposits obtained by wire and arc additive manufacturing using a Cold Metal Transfer process. Science and Tecbnology of Welding and Joining, Vol. 24, No. 6, pp. 538-547. doi: 10.1080/13621718.2018.1564986.

[7] MA, G., ZHAO, G., LI, Z., YANG, M., \& XIAO, W. (2019). Optimization strategies for robotic additive and subtractive manufacturing of large and high thin-walled aluminum structures. The International Journal of Advanced Manufacturing Technology, Vol. 101, No. 5-8, pp. 12751292. doi: 10.1007/s00170-018-3009-3.

[8] KUMAR, A., \& MAJI, K. (2020). Selection of Process Parameters for Near-Net Shape Deposition in Wire Arc Additive Manufacturing by Genetic Algorithm. Journal of Materials Engineering and Performance, Vol. 29, No. 5, pp. 3334 3352. doi: 10.1007/s11665-020-04847-1.

[9] JIN, W., ZHANG, C., JIN, S., TIAN, Y., WELLMANN, D., \& LIU, W. (2020). Wire Arc Additive Manufacturing of Stainless Steels: A Review. Applied Sciences, Vol. 10. No. 5, pp. 1563. doi: 10.3390/app100515 63.

[10] SUN, L., JIANG, F., HUANG, R., YUAN, D., SU, Y., GUO, C., \& WANG, J. (2020). Investigation on the process window with liner energy density for single-layer parts fabricated by wire and arc additive manufacturing. Joumal of Manufacturing Processes, Vol 56, No. April 2019, pp. 898-907. doi: 10.1016/j.jmapro.202 0.05.054.

[11] WANG, J., SUN, Q., MA, J., JIN, P., SUN, T., \& FENG, J. (2019). Correlation between wire feed speed and external mechanical constraint for enhanced process stability in underwater wet flux-cored arc welding. Proceedings of the Institution of Mechanical Engineers, Part B: Journal of Engineering Manufacture, Vol. 233, No. 10, pp. 2061-2073. doi: 10.1177/0954405418811783.

[12] LI, F., CHEN, S., SHI, J., ZHAO, Y., \& TIAN, H. (2018). Thermoelectric Cooling-Aided Bead Geometry Regulation in Wire and Arc-Based Additive Manufacturing of Thin-Walled Structures. Applied Sciences, Vol. 8, No. 2, pp. 207. doi: $10.3390 /$ app8020207.
[13] DINOVITZER, M., CHEN, X., LALIBERTE, J., HUANG, X., \& FREI, H. (2019). Effect of Wire and Arc Additive Manufacturing ( WAAM ) Process Parameters on Bead Geometry and Microstructure. Additive Manufacturing, Vol. 26. No. February, pp. 138146. doi: 10.1016/j.addma.2018.12.013.

[14] WANG, H., JIANG, W., OUYANG, J., \& KOVACEVIC, R. (2004). Rapid prototyping of 4043 Al-alloy parts by VP-GTAW. Journal of Materials Processing Technology, Vol. 148, No. 1, pp. 93-102. doi: 10.1016/j.jmatprotec.20 04.01.058.

[15] KNEZOVIC, N., \& DOLSAK, B. (2018). Inprocess non-destructive ultrasonic testing application during wire plus arc additive manufacturing. Advances in Production Engineering \& Management, Vol. 13. No. 2, pp. 158-168. doi:10.14743/apem2018.2.281.

[16] GOMEZ, A. O., GALVAN, L. C., DESCHAUX-BEAUME, F., MEZRAG, B., \& ROUQUETTE, S. (2018). Effect of process parameters on the quality of aluminium alloy Al5Si deposits in wire and arc additive manufacturing using a cold metal transfer process. Science and Technology of Welding and Joining, Vol. 23, No. 4, pp. 316-332. doi: 10.1080/13621718.2017.1388995.

[17] SARATHCHANDRA, D. T., DAVIDSON, M. J., \& VISVANATHAN, G. (2020). Parameters effect on SS304 beads deposited by wire arc additive manufacturing. Materials and Manufacturing Processes, Vol. 35. No. 7, pp. 852-858. doi: 10.1080/10426914.2020.1743852.

[18] ROSLI, N. A., ALKAHARI, M. R., ABDOLLAH, M. F. BIN, MAIDIN, S., RAMLI, F. R., \& HERAWAN, S. G. (2021). Review on effect of heat input for wire arc additive manufacturing process. Journal of Materials Research and Technology, Vol. 11,pp. 2127-2145. doi:10.1016/j.jmrt.2021.02.002.

[19] MÜLLER, J., GRABOWSKI, M., MÜLLER, C., HENSEL, J., UNGLAUB, J., THIELE, K., KLOFT, H., \& DILGER, K. (2019). Design and parameter identification of wire and arc additively manufactured (WAAM) steel bars for use in construction. Metals. doi: 10.3390/met 9070725 .

[20] LIU, G., \& XIONG, J. (2020). External filler wire based GMA-AM process of 2219 aluminum alloy. Materials and Manufacturing Processes, Vol. 35. No. 11, pp. 1268-1277. doi: 10.1080/10426914.2020.1779936. 
[21] NAZAN, M. A., RAMLI, F. R., ALKAHARI, M. R., SUDIN, M. N., \& ABDULLAAH, M. A. (2017). Process parameter optimization of 3D printer using Response Surface Method. ARPN Journal of Engineering and Applied Sciences, Vol. 12. No. 7, pp. 2291-2296.

[22] ROSLI, N. A., ALKAHARI, M. R., RAMLI, F. R., MAIDIN, S., SUDIN, M. N., SUBRAMONIAM, S., \& FURUMOTO, T. (2018). Design and Development of a LowCost 3D Metal Printer. Journal of Mechanical Engineering Research and Developments, 41(3), 47-54. doi: 10.26480/jmerd.03.2018.47.54.

[23] TANG, S., WANG, G., HUANG, C., LI, R., ZHOU, S., AND ZHANG, H., (2020). Investigation, modeling and optimization of abnormal areas of weld beads in wire and arc additive manufacturing. Rapid Prototyping Journal, Vol. 26. No. 7, pp. 1183-1195. doi: 10.1108/RPJ-082019-0229.

[24] BENAKIS, M., COSTANZO, D., \& PATRAN, A. (2020). Current mode effects on weld bead geometry and heat affected zone in pulsed wire arc additive manufacturing of Ti-64 and Inconel 718. Journal of Manufacturing Processes, Vol. 60. No. July, pp. 61-74. doi: 10.1016/j.jmapro.2020.10.018.

[25] ALI, Y., HENCKELL, P., HILDEBRAND, J., REIMANN, J., BERGMANN, J. P., \& BARNIKOL-OETTLER, S. (2019). Wire arc additive manufacturing of hot work tool steel with CMT process. Journal of Materials Processing Technology, Vol. 269. No. July 2018, pp. 109116. doi: 10.1016/j.jmatprotec.2019.01.034.

[26] SPANIOL, E., UNGETHÜM, T., TRAUTMANN, M., ANDRUSCH, K.,
HERTEL, M., \& FÜSSEL, U. (2020). Development of a novel TIG hot-wire process for wire and arc additive manufacturing. Welding in the World, Vol. 64. No. 8, pp. 1329-1340. doi: 10.1007/s40194-020-00871-w.

[27] WU, B., DING, D., PAN, Z., CUIURI, D., LI, H., HAN, J., \& FEI, Z. (2017). Effects of heat accumulation on the arc characteristics and metal transfer behavior in Wire Arc Additive Manufacturing of Ti6Al4V. Journal of Materials Processing Technology, Vol. 250, pp. 304-312. doi: 10.1016/j.jmatprotec.2017.07.037.

[28] WANG, L. L., WEI, J. H., \& WANG, Z. M. (2018). Numerical and experimental investigations of variable polarity gas tungsten arc welding. The International Journal of Advanced Manufacturing Technology, Vol. 95. No. 5-8, pp. 24212428. doi: 10.1007/s00170-017-1387-6.

[29] CORRADI, D. R., BRACARENSE, A. Q., WU, B., CUIURI, D., PAN, Z., \& LI, H. (2020). Effect of Magnetic Arc Oscillation on the geometry of single-pass multi-layer walls and the process stability in wire and arc additive manufacturing. Journal of Materials Processing Technology, Vol. 283. No. December 2019, pp. 116723. doi: 10.1016/j.jmatprotec.2020.116723.

[30] SU, C., \& CHEN, X. (2019). Effect of depositing torch angle on the first layer of wire arc additive manufacture using cold metal transfer (CMT). Industrial Robot: The International Journal of Robotics Research and Application, Vol. 46. No. 2, pp. 259-266. doi: 10.1108/IR-11-20180233. 